\title{
Some new results on cyclic relatively nonexpansive mappings in convex metric spaces
}

\author{
Moosa Gabeleh and Naseer Shahzad ${ }^{2 *}$
}

"Correspondence:

nshahzad@kau.edu.sa

2Department of Mathematics, King

Abdulaziz University, P.O. Box 80203,

Jeddah, 21589, Saudi Arabia

Full list of author information is

available at the end of the article

\begin{abstract}
In this article, we prove a best proximity point theorem for generalized cyclic contractions in convex metric spaces. Then we investigate the structure of minimal sets of cyclic relatively nonexpansive mappings in the setting of convex metric spaces. In this way, we obtain an extension of the Goebel-Karlovitz lemma, which is a key lemma in fixed point theory.

MSC: 47H10; 47H09; 46B2O
\end{abstract}

Keywords: best proximity point; cyclic relatively nonexpansive mapping; convex metric space

\section{Introduction}

Let $(X, d)$ be a metric space, and let $A, B$ be subsets of $X$. A mapping $T: A \cup B \rightarrow A \cup B$ is said to be cyclic provided that $T(A) \subseteq B$ and $T(B) \subseteq A$. We begin by recalling the following extension of the Banach contraction principle.

Theorem 1.1 ([1]) Let $A$ and $B$ be nonempty closed subsets of a complete metric space $(X, d)$. Suppose that $T$ is a cyclic mapping such that

$$
d(T x, T y) \leq \alpha d(x, y)
$$

for some $\alpha \in(0,1)$ and for all $x \in A, y \in B$. Then $T$ has a unique fixed point in $A \cap B$.

In [2] Eldred and Veeramani introduced the class of cyclic contractions. Before stating the definition we recall that

$$
\operatorname{dist}(A, B):=\inf \{d(x, y): x \in A, y \in B\}
$$

denotes the distance between the subsets $A$ and $B$ of $X$.

Definition 1.2 Let $A$ and $B$ be nonempty subsets of a metric space $X$. A mapping $T$ : $A \cup B \rightarrow A \cup B$ is said to be a cyclic contraction if $T$ is cyclic and

$$
d(T x, T y) \leq \alpha d(x, y)+(1-\alpha) \operatorname{dist}(A, B)
$$

for some $\alpha \in(0,1)$ and for all $x \in A, y \in B$.

C) 2014 Gabeleh and Shahzad; licensee Springer. This is an Open Access article distributed under the terms of the Creative Commons Attribution License (http://creativecommons.org/licenses/by/2.0), which permits unrestricted use, distribution, and reproduction in any medium, provided the original work is properly cited. 
Let $T$ be a cyclic mapping. A point $x \in A \cup B$ is said to be a best proximity point for $T$ provided that $d(x, T x)=\operatorname{dist}(A, B)$.

For a uniformly convex Banach space $X$, Eldred and Veeramani proved the following theorem.

Theorem 1.3 ([2]) Let $A$ and $B$ be nonempty, closed, and convex subsets of a uniformly convex Banach space $X$ and let $T: A \cup B \rightarrow A \cup B$ be a cyclic contraction map. For $x_{0} \in A$, define $x_{n+1}:=T x_{n}$ for each $n \geq 0$. Then there exists a unique $x \in A$ such that $x_{2 n} \rightarrow x$ and $\|x-T x\|=\operatorname{dist}(A, B)$.

An interesting extension of Theorem 1.3 can be found in $[3,4]$.

Recently, Suzuki et al. in [5] introduced the notion of the property UC, which is a kind of geometric property for subsets of a metric space $X$.

Definition 1.4 ([5]) Let $A$ and $B$ be nonempty subsets of a metric space $(X, d)$. Then $(A, B)$ is said to satisfy property $\mathrm{UC}$ if the following holds:

If $\left\{x_{n}\right\}$ and $\left\{z_{n}\right\}$ are sequences in $A$ and $\left\{y_{n}\right\}$ is a sequence in $B$ such that $\lim _{n} d\left(x_{n}, y_{n}\right)=$ $\operatorname{dist}(A, B)$ and $\lim _{n} d\left(z_{n}, y_{n}\right)=\operatorname{dist}(A, B)$, then we have $\lim _{n} d\left(x_{n}, z_{n}\right)=0$.

We mention that if $A$ and $B$ are nonempty subsets of a uniformly convex Banach space $X$ such that $A$ is convex, then $(A, B)$ satisfies the property UC. Other examples of pairs having the property UC can be found in [5].

The next theorem guarantees the existence, uniqueness, and convergence of a best proximity point for cyclic contractions in metric spaces by using the notion of the property UC.

Theorem 1.5 ([5]) Let $(X, d)$ be a metric space and let $A$ and $B$ be nonempty subsets of $X$ such that $(A, B)$ satisfies the property $\mathrm{UC}$. Assume that $A$ is complete. Let $T: A \cup B \rightarrow A \cup B$ be a generalized cyclic contraction, that is, there exists $r \in[0,1)$ such that

$$
d(T x, T y) \leq r \max \{d(x, y), d(x, T x), d(y, T y)\}+(1-r) \operatorname{dist}(A, B)
$$

for all $x \in A$ and $y \in B$. Then $T$ has a unique best proximity point $z$ in $A$, and for every $x \in A$ the sequence $\left\{T^{2 n} x\right\}$ converges to $z$.

We mention that in [6] the authors proved Theorem 1.5 without using property UC and obtained the existence and not convergence of best proximity points for generalized cyclic contractions in Banach spaces (for more information one can refer to [7]).

We also recall that the weaker notion of the property UC was introduced in [8], called the WUC property, in order to study of the existence, uniqueness, and convergence of a best proximity point for cyclic contraction mappings.

Let $(A, B)$ be a nonempty pair of subsets of a metric space $(X, d)$. A mapping $T: A \cup B \rightarrow$ $A \cup B$ is said to be a cyclic relatively nonexpansive if $T$ is cyclic and $d(T x, T y) \leq d(x, y)$ for all $(x, y) \in A \times B$. It is clear that every nonexpansive mapping is relatively nonexpansive.

Eldred et al. [9] established the existence of best proximity points for cyclic relatively nonexpansive mappings by using a geometric notion of proximal normal structure in the setting of Banach spaces. For related results, we refer the reader to [10-18]. 
In this article, motivated by Theorem 1.5 , we establish a best proximity point theorem for generalized cyclic contraction mappings in convex metric spaces. We also study the structure of minimal sets for cyclic relatively nonexpansive mappings. In this way, we obtain an extension of the Goebel-Karlovitz lemma which plays an important role in fixed point theory.

\section{Preliminaries}

The notion of convexity in metric spaces was introduced by Takahashi as follows.

Definition 2.1 ([19]) Let $(X, d)$ be a metric space and $I:=[0,1]$. A mapping $\mathcal{W}: X \times X \times$ $I \rightarrow X$ is said to be a convex structure on $X$ provided that, for each $(x, y ; \lambda) \in X \times X \times I$ and $u \in X$,

$$
d(u, \mathcal{W}(x, y ; \lambda)) \leq \lambda d(u, x)+(1-\lambda) d(u, y) .
$$

A metric space $(X, d)$ together with a convex structure $\mathcal{W}$ is called a convex metric space, which is denoted by $(X, d, \mathcal{W})$. A Banach space and each of its convex subsets are convex metric spaces. But a Fréchet space is not necessarily a convex metric space. Other examples of convex metric spaces which are not embedded in any Banach space can be found in [19].

Here, we recall some notations and definitions of $[6,19]$.

Definition $2.2([19])$ A subset $K$ of a convex metric space $(X, d, \mathcal{W})$ is said to be a convex set provided that $\mathcal{W}(x, y ; \lambda) \in K$ for all $x, y \in K$ and $\lambda \in I$.

Proposition 2.3 ([19]) Let $(X, d, \mathcal{W})$ be a convex metric space and let $B(x ; r)$ denote the closed ball centered at $x \in X$ with radius $r \geq 0$. Then $B(x ; r)$ is a convex subset of $X$.

Proposition 2.4 ([19]) Let $\left\{K_{\alpha}\right\}_{\alpha \in A}$ be a family of convex subsets of $X$, then $\bigcap_{\alpha \in A} K_{\alpha}$ is also a convex subset of $X$.

Definition 2.5 ([19]) A convex metric space $(X, d, \mathcal{W})$ is said to have property $(C)$ if every bounded decreasing net of nonempty, closed, and convex subsets of $X$ has a nonempty intersection.

For example every weakly compact convex subset of a Banach space has property (C). The next example ensures that condition $(C)$ is natural as well in the metrical setting.

Example 2.1 ([20]) Let $\mathcal{H}$ be a Hilbert space and let $X$ be a nonempty closed subset of $\{x \in \mathcal{H}:\|x\|=1\}$ such that if $x, y \in X$ and $\alpha, \beta \in[0,1]$ with $\alpha+\beta=1$, then $\frac{\alpha x+\beta y}{\|\alpha x+\beta y\|} \in X$ and $\operatorname{diam}(X) \leq \frac{\sqrt{2}}{2}$, where $\operatorname{diam}(X):=\sup \{d(x, y): x, y \in X\}$. Let $d(x, y):=\cos ^{-1}(\langle x, y\rangle)$ for all $x, y \in X$, where $\langle\cdot, \cdot\rangle$ is the inner product of $\mathcal{H}$. If we define the convex structure $\mathcal{W}$ : $X \times X \times I \rightarrow X$ with $\mathcal{W}(x, y, \lambda):=\frac{\lambda x+(1-\lambda) y}{\|\lambda x+(1-\lambda) y\|}$, then $(X, d)$ is a complete convex metric space which has the property (C) (for more information see Example 2 of [20]).

Let $A$ and $B$ be two nonempty subsets of a convex metric space $(X, d, \mathcal{W})$. We shall say that a pair $(A, B)$ in a convex metric space $(X, d, \mathcal{W})$ satisfies a property if both $A$ and $B$ 
satisfy that property. For instance, $(A, B)$ is convex if and only if both $A$ and $B$ are convex; $(A, B) \subseteq(C, D) \Leftrightarrow A \subseteq C$, and $B \subseteq D$. We shall also adopt the following notations:

$$
\begin{aligned}
& \delta_{x}(A):=\sup \{d(x, y): y \in A\} \quad \text { for all } x \in X, \\
& \delta(A, B):=\sup \{d(x, y): x \in A, y \in B\}, \\
& \operatorname{diam}(A):=\delta(A, A) .
\end{aligned}
$$

The closed and convex hull of a set $A$ will be denoted by $\overline{\operatorname{con}}(A)$ and is defined by

$$
\overline{\operatorname{con}}(A):=\bigcap\{C: C \text { is a closed and convex subset of } X \text { such that } C \supseteq A\} .
$$

The pair $(x, y) \in A \times B$ is said to be proximal in $(A, B)$ if $d(x, y)=\operatorname{dist}(A, B)$. Moreover, we set

$$
\begin{aligned}
& A_{0}:=\left\{x \in A: d\left(x, y^{\prime}\right)=\operatorname{dist}(A, B), \text { for some } y^{\prime} \in B\right\}, \\
& B_{0}:=\left\{y \in B: d\left(x^{\prime}, y\right)=\operatorname{dist}(A, B), \text { for some } x^{\prime} \in A\right\} .
\end{aligned}
$$

Note that if $(A, B)$ is a nonempty, weakly compact, and convex pair of subsets of a Banach space $X$, then so is the pair $\left(A_{0}, B_{0}\right)$, and it is easy to see that $\operatorname{dist}(A, B)=\operatorname{dist}\left(A_{0}, B_{0}\right)$.

Definition 2.6 A pair of sets $(A, B)$ is said to be proximal if $A=A_{0}$ and $B=B_{0}$.

The following result follows from the proof of Theorem 2.1 in [9].

Lemma 2.7 Let $(A, B)$ be a nonempty weakly compact convex pair of a Banach space $X$ and $T: A \cup B \rightarrow A \cup B$ a cyclic relatively nonexpansive mapping. Then there exists $\left(K_{1}, K_{2}\right) \subseteq$ $\left(A_{0}, B_{0}\right) \subseteq(A, B)$ which is minimal with respect to being nonempty, closed, convex, and a $T$-invariant pair of subsets of $(A, B)$ such that

$$
\operatorname{dist}\left(K_{1}, K_{2}\right)=\operatorname{dist}(A, B) .
$$

Moreover, the pair $\left(K_{1}, K_{2}\right)$ is proximal.

Definition 2.8 ([21]) Let $(A, B)$ be a nonempty pair of subsets of a metric space $(X, d)$. We say that the pair $(A, B)$ is proximal compactness provided that every net $\left(\left\{x_{\alpha}\right\},\left\{y_{\alpha}\right\}\right)$ of $A \times B$ satisfying the condition that $d\left(x_{\alpha}, y_{\alpha}\right) \rightarrow \operatorname{dist}(A, B)$, has a convergent subnet in $A \times B$. Also, we say that $A$ is semi-compactness if $(A, A)$ is proximal compactness.

It is clear that if $(A, B)$ is a compact pair in a metric space $(X, d)$ then $(A, B)$ is proximal compactness.

Definition 2.9 Let $(A, B)$ be a nonempty pair of sets in a Banach space $X$. A point $p$ in $A$ ( $q$ in $B$ ) is said to be a diametral point with respect to $B$ (w.r.t. $A$ ) if $\delta_{p}(B)=\delta(A, B)$ $\left(\delta_{q}(A)=\delta(A, B)\right)$. A pair $(p, q)$ in $A \times B$ is diametral if both points $p$ and $q$ are diametral. 


\section{Main results}

In this section, we study the structure of minimal sets of cyclic relatively nonexpansive mappings in the setting of convex metric spaces.

\subsection{Generalized cyclic contractions in convex metric spaces}

We begin our main results of this paper with the following existence theorem.

Theorem 3.1 Let $(A, B)$ be a nonempty, bounded, closed, and convex pair in a convex metric space $(X, d, \mathcal{W})$. Suppose that $T: A \cup B \rightarrow A \cup B$ is a generalized cyclic contraction. If $X$ has the property $(C)$ then $T$ has a best proximity pair.

Proof Let $\Sigma$ denote the set of all nonempty, bounded, closed, and convex pairs $(E, F)$ which are subsets of $(A, B)$ such that $T$ is cyclic on $E \cup F$. Note that $(A, B) \in \Sigma$. Also, $\Sigma$ is partially ordered by reverse inclusion, that is, $\left(E_{1}, F_{1}\right) \leq\left(E_{2}, F_{2}\right) \Leftrightarrow\left(E_{2}, F_{2}\right) \subseteq\left(E_{1}, F_{1}\right)$. By the fact that $X$ has the property $(C)$, every increasing chain in $\Sigma$ is bounded above. So, by using Zorn's lemma we obtain a maximal element, say $(C, D) \in \Sigma$. We note that $(\overline{\operatorname{con}}(T(D)), \overline{\operatorname{con}}(T(C)))$ is a nonempty, bounded, closed, and convex pair in $X$ and $(\overline{\operatorname{con}}(T(D)), \overline{\operatorname{con}}(T(C))) \subseteq(C, D)$. Furthermore,

$$
T(\overline{\operatorname{con}}(T(D))) \subseteq T(C) \subseteq \overline{\operatorname{con}}(T(C))
$$

and also

$$
T(\overline{\operatorname{con}}(T(C))) \subseteq \overline{\operatorname{con}}(T(D))
$$

that is, $T$ is cyclic on $\overline{\operatorname{con}}(T(D)) \cup \overline{\operatorname{con}}(T(C))$. It now follows from the maximality of $(C, D)$ that

$$
\overline{\operatorname{con}}(T(D))=C, \quad \overline{\operatorname{con}}(T(C))=D
$$

Let $x \in C$, then $D \subseteq B\left(x ; \delta_{x}(D)\right)$. Now, if $y \in D$ we have

$$
\begin{aligned}
d(T x, T y) & \leq r \max \{d(x, y), d(x, T x), d(T y, y)\}+(1-r) \operatorname{dist}(A, B) \\
& \leq r \delta(C, D)+(1-r) \operatorname{dist}(A, B) .
\end{aligned}
$$

Therefore, for all $y \in D$ we have

$$
T y \in B(T x ; r \delta(C, D)+(1-r) \operatorname{dist}(A, B)),
$$

and then

$$
T(D) \subseteq B(T x ; r \delta(C, D)+(1-r) \operatorname{dist}(A, B)) .
$$

Thus,

$$
C=\overline{\operatorname{con}}(T(D)) \subseteq B(T x ; r \delta(C, D)+(1-r) \operatorname{dist}(A, B)),
$$


from which one concludes that

$$
d(z, T x) \leq r \delta(C, D)+(1-r) \operatorname{dist}(A, B), \quad \text { for all } z \in C .
$$

So,

$$
\delta_{T x}(C) \leq r \delta(C, D)+(1-r) \operatorname{dist}(A, B) .
$$

Similarly, if $y \in D$ we obtain

$$
\delta_{T y}(D) \leq r \delta(C, D)+(1-r) \operatorname{dist}(A, B) .
$$

Put

$$
\begin{aligned}
& E:=\left\{x \in C: \delta_{x}(D) \leq r \delta(C, D)+(1-r) \operatorname{dist}(A, B)\right\}, \\
& F:=\left\{y \in D: \delta_{y}(C) \leq r \delta(C, D)+(1-r) \operatorname{dist}(A, B)\right\} .
\end{aligned}
$$

Note that $T(D) \subseteq E$ and $T(C) \subseteq F$ and we have

$$
\begin{aligned}
& E=\bigcap_{y \in D} B(y ; r \delta(C, D)+(1-r) \operatorname{dist}(A, B)) \cap C, \\
& F=\bigcap_{x \in C} B(x ; r \delta(C, D)+(1-r) \operatorname{dist}(A, B)) \cap D .
\end{aligned}
$$

Further, if $x \in E$ then by (3), $T x \in F$, i.e. $T(E) \subseteq F$ and also, by (4), $T(F) \subseteq E$. This proves that $T$ is cyclic on $E \cup F$. Maximality of $(C, D)$ implies that $E=C$ and $F=D$. We now conclude that

$$
\delta_{x}(D) \leq r \delta(C, D)+(1-r) \operatorname{dist}(A, B), \quad \text { for all } x \in C .
$$

So,

$$
\delta(C, D)=\operatorname{dist}(A, B) .
$$

Now, for each pair $(p, q) \in C \times D$ we must have

$$
d(p, T p)=d(T q, q)=\operatorname{dist}(A, B)
$$

which completes the proof of the theorem.

Remark 3.1 Note that Theorem 3.1 holds once the maximal sets $K_{1}$ and $K_{2}$ have been fixed and the cyclic mapping $T: A \cup B \rightarrow A \cup B$ satisfies the condition that there exists $r \in[0,1)$ such that

$$
d(T x, T y) \leq r \delta\left(K_{1}, K_{2}\right)+(1-r) \operatorname{dist}(A, B),
$$

for all $(x, y) \in A \times B$. 
The next corollary, obtained from Theorem 3.1, immediately follows.

Corollary 3.2 Let $(A, B)$ be a nonempty, bounded, closed, and convex pair in a reflexive Banach space $X$. Suppose that $T: A \cup B \rightarrow A \cup B$ is a generalized cyclic contraction. Then $T$ has a best proximity point.

Let us illustrate Theorem 3.1 with the following example.

Example 3.1 Let $X:=[-1,1]$ and define a metric $d$ on $X$ by

$$
d(x, y)= \begin{cases}0, & \text { if } x=y, \\ \max \{|x|,|y|\}, & \text { if } x \neq y .\end{cases}
$$

Define $\mathcal{W}: X \times X \times I \rightarrow X$ with

$$
\mathcal{W}(x, y, \lambda)=\lambda \min \{|x|,|y|\},
$$

for each $x, y \in X$ and $\lambda \in I$ (see [22]). Then $\mathcal{W}$ is a convex stricture on $X$. In this order, let $x, y \in X$ and $\lambda \in I$. We may assume that $|x| \leq|y|$. Then for each $u \in X$ we have

$$
\begin{aligned}
d(u, \mathcal{W}(x, y, \lambda)) & =\max \{|u|, \lambda \min \{|x|,|y|\}\} \\
& =\max \{|u|, \lambda|x|\} \leq \max \{|u|,|x|\} \\
& =\lambda \max \{|u|,|x|\}+(1-\lambda) \max \{|u|,|x|\} \\
& \leq \lambda \max \{|u|,|x|\}+(1-\lambda) \max \{|u|,|y|\} \\
& =\lambda d(u, x)+(1-\lambda) d(u, y) .
\end{aligned}
$$

This implies that $(X, d, \mathcal{W})$ is a convex metric space. Now, let $E$ be a nonempty convex subset of $X$. Then $\mathcal{W}(x, y, \lambda) \in E$ for each $x, y \in E$ and $\lambda \in I$. If $\lambda=0$, then we conclude that $0 \in E$. Therefore, the convex metric space $(X, d, \mathcal{W})$ must have the property $(C)$. Suppose that $A:=[0,1]$ and $B:=\{-1,0\}$. Then $(A, B)$ is a bounded, closed, and convex pair of subsets of $X$. Let $T: A \cup B \rightarrow A \cup B$ be a mapping defined by

$$
T x= \begin{cases}0, & \text { if } x \in A \\ \frac{1}{2}, & \text { if } x=-1\end{cases}
$$

Clearly, $T$ is cyclic on $A \cup B$. On the other hand, $T$ is generalized cyclic contraction for each $r \in\left[\frac{1}{2}, 1\right)$. It now follows from Theorem 3.1 that $T$ has a best proximity point which is a fixed point in this case.

\subsection{Extension of Goebel-Karlovitz lemma}

The following result is another version of Lemma 2.7 in the setting of convex metric spaces.

Lemma 3.3 Let $(A, B)$ be a nonempty, bounded, closed, and convex pair of a convex metric space $(X, d, \mathcal{W})$ such that $A_{0}$ is nonempty and $(A, B)$ is proximal compactness. Assume that 
$T: A \cup B \rightarrow A \cup B$ is a cyclic relatively nonexpansive mapping. If $X$ has the property $(C)$ then there exists a pair $\left(K_{1}, K_{2}\right) \subseteq(A, B)$ which is minimal with respect to being nonempty, closed, convex, and a $T$-invariant pair of subsets of $(A, B)$ such that

$$
\operatorname{dist}\left(K_{1}, K_{2}\right)=\operatorname{dist}(A, B) .
$$

Proof Let $\Sigma$ denote the set of all nonempty, closed, and convex pairs $(E, F)$ which are subsets of $(A, B)$ such that $T$ is cyclic on $E \cup F$ and $d(x, y)=\operatorname{dist}(A, B)$ for some $(x, y) \in$ $E \times F$. Note that $(A, B) \in \Sigma$ by the fact that $A_{0}$ is nonempty. Also, $\Sigma$ is partially ordered by reverse inclusion. Assume that $\left\{\left(E_{\alpha}, F_{\alpha}\right)\right\}_{\alpha}$ is a increasing chain in $\Sigma$. Set $E:=\bigcap E_{\alpha}$ and $F:=\bigcap F_{\alpha}$. Since $X$ has the property $(C)$, we conclude that $(E, F)$ is a nonempty pair. Also, by Proposition 2.4, $(E, F)$ is a closed and convex pair. Moreover,

$$
T(E)=T\left(\bigcap E_{\alpha}\right) \subseteq \bigcap T\left(E_{\alpha}\right) \subseteq \bigcap F_{\alpha}=F .
$$

Similarly we can see that $T(F) \subseteq E$, that is, $T$ is cyclic on $E \cup F$. Now, let $\left(x_{\alpha}, y_{\alpha}\right) \in E_{\alpha} \times$ $F_{\alpha}$ be such that $d\left(x_{\alpha}, y_{\alpha}\right)=\operatorname{dist}(A, B)$. Since $(A, B)$ is proximal compactness, $\left(x_{\alpha}, y_{\alpha}\right)$ has a convergent subsequence, say $\left(x_{\alpha_{i}}, y_{\alpha_{i}}\right)$, such that $x_{\alpha_{i}} \rightarrow x \in A$ and $y_{\alpha_{i}} \rightarrow y \in B$. Thus,

$$
d(x, y)=\lim _{i} d\left(x_{\alpha_{i}}, y_{\alpha_{i}}\right)=\operatorname{dist}(A, B) .
$$

Therefore, there exists an element $(x, y) \in E \times F$ such that $d(x, y)=\operatorname{dist}(A, B)$. Hence, every increasing chain in $\Sigma$ is bounded above with respect to a reverse inclusion relation. Then by using Zorn's lemma we can get a maximal element, say $\left(K_{1}, K_{2}\right)$, which is minimal with respect to set inclusion and so, is minimal with respect to being nonempty, closed, convex, and a $T$-invariant pair of subsets of $(A, B)$ such that

$$
\operatorname{dist}\left(K_{1}, K_{2}\right)=\operatorname{dist}(A, B) .
$$

Lemma 3.4 Let $(A, B)$ be a nonempty, bounded, closed, and convex pair of a convex metric space $(X, d, \mathcal{W})$ such that $A_{0}$ is nonempty, $X$ has the property $(C)$ and $(A, B)$ is proximal compactness. Let $T: A \cup B \rightarrow A \cup B$ be a cyclic relatively nonexpansive mapping. Suppose that $\left(K_{1}, K_{2}\right) \subseteq(A, B)$ is a minimal, closed, convex pair which is $T$-invariant such that $\operatorname{dist}\left(K_{1}, K_{2}\right)=\operatorname{dist}(A, B)$. Then each pair $(p, q) \in K_{1} \times K_{2}$ with $d(p, q)=\operatorname{dist}(A, B)$ contains a diametral point (with respect to $\left.\left(K_{1}, K_{2}\right)\right)$.

Proof By the fact that $T$ is cyclic, a similar argument to Theorem 3.1 implies that $T$ is also cyclic on $\overline{\operatorname{con}}\left(T\left(K_{1}\right)\right) \cup \overline{\operatorname{con}}\left(T\left(K_{2}\right)\right)$. Let $\left(x_{0}, y_{0}\right) \in K_{1} \times K_{2}$ be such that $d\left(x_{0}, y_{0}\right)=\operatorname{dist}(A, B)$. The relatively nonexpansiveness of $T$ implies that

$$
\begin{aligned}
\operatorname{dist}(A, B) & \leq \operatorname{dist}\left(\overline{\operatorname{con}}\left(T\left(K_{2}\right)\right), \overline{\operatorname{con}}\left(T\left(K_{1}\right)\right)\right) \\
& \leq d\left(T y_{0}, T x_{0}\right) \leq d\left(x_{0}, y_{0}\right)=\operatorname{dist}(A, B) .
\end{aligned}
$$

So, $\operatorname{dist}\left(\overline{\operatorname{con}}\left(T\left(K_{2}\right)\right), \overline{\operatorname{con}}\left(T\left(K_{1}\right)\right)\right)=\operatorname{dist}(A, B)$. Now, by the minimality of $\left(K_{1}, K_{2}\right)$, we must have

$$
\overline{\operatorname{con}}\left(T\left(K_{1}\right)\right)=K_{2}, \quad \overline{\operatorname{con}}\left(T\left(K_{2}\right)\right)=K_{1} .
$$


Assume that $(p, q) \in K_{1} \times K_{2}$ such that $d(p, q)=\operatorname{dist}(A, B)$ and suppose there is no diametral point in $(p, q)$, that is,

$$
\max \left\{\delta_{p}\left(K_{2}\right), \delta_{q}\left(K_{1}\right)\right\}<\delta\left(K_{1}, K_{2}\right) .
$$

Put $r_{1}:=\delta_{p}\left(K_{2}\right)$ and $r_{2}:=\delta_{q}\left(K_{1}\right)$. Let $r:=\max \left\{r_{1}, r_{2}\right\}<\delta\left(K_{1}, K_{2}\right)$ and define

$$
C_{r}\left(K_{2}\right):=K_{1} \cap\left(\bigcap_{x \in K_{2}} B(x ; r)\right), \quad C_{r}\left(K_{1}\right):=K_{2} \cap\left(\bigcap_{x \in K_{1}} B(x ; r)\right) .
$$

Note that $\left(C_{r}\left(K_{2}\right), C_{r}\left(K_{1}\right)\right)$ is a nonempty, closed, and convex pair in $X$ by Propositions 2.3 and 2.4, and since $(p, q) \in\left(C_{r}\left(K_{2}\right), C_{r}\left(K_{1}\right)\right)$,

$$
\operatorname{dist}\left(C_{r}\left(K_{2}\right), C_{r}\left(K_{1}\right)\right)=\operatorname{dist}(A, B) .
$$

It is not difficult to see that, for $(x, y) \in K_{1} \times K_{2}$,

$$
(x, y) \in\left(C_{r}\left(K_{2}\right), C_{r}\left(K_{1}\right)\right) \quad \Leftrightarrow \quad K_{2} \subseteq B(x ; r), \quad K_{1} \subseteq B(y ; r) .
$$

We now prove that $T$ is cyclic on $C_{r}\left(K_{2}\right) \cup C_{r}\left(K_{1}\right)$. Let $u \in C_{r}\left(K_{2}\right)$. We must verify that $T u \in C_{r}\left(K_{1}\right)$, that is, $K_{1} \subseteq B(T u ; r)$. By the relatively nonexpansiveness of $T$, for $v \in K_{2}$ we have

$$
d(T v, T u) \leq d(u, v) \leq r,
$$

then $T v \in B(T u ; r)$, which implies that $T\left(K_{2}\right) \subseteq B(T u ; r)$. Therefore, $K_{1}=\overline{\operatorname{cov}}\left(T\left(K_{2}\right)\right) \subseteq$ $B(T u ; r)$ and hence, $T u \in C_{r}\left(K_{1}\right)$. Thus, $T\left(C_{r}\left(K_{2}\right)\right) \subseteq C_{r}\left(K_{1}\right)$. Similarly, we can see that $T\left(C_{r}\left(K_{1}\right)\right) \subseteq C_{r}\left(K_{2}\right)$. Therefore, $T$ is cyclic on $C_{r}\left(K_{1}\right) \cup C_{r}\left(K_{2}\right)$. Now, the minimality of $\left(K_{1}, K_{2}\right)$ implies that $C_{r}\left(K_{1}\right)=K_{2}$ and $C_{r}\left(K_{2}\right)=K_{1}$. Hence, $K_{2} \subseteq \bigcap_{x \in K_{1}} B(x ; r)$ and so, for each $y \in K_{2}, \delta_{y}\left(K_{1}\right) \leq r$. Therefore, we obtain

$$
\delta\left(K_{1}, K_{2}\right)=\sup _{y \in K_{2}} \delta_{y}\left(K_{1}\right) \leq r,
$$

which is a contradiction. Thus, our assumption was wrong and either $p$ or $q$ must be a diametral point for $\left(K_{1}, K_{2}\right)$.

Definition 3.5 Let $(A, B)$ be a nonempty pair of subsets of a metric space $(X, d)$. Suppose that $T: A \cup B \rightarrow A \cup B$ is a cyclic mapping. Then a sequence $\left\{x_{n}\right\}$ in $A \cup B$ is said to be an approximate best proximity point sequence for $T$ if

$$
\lim _{n \rightarrow \infty} d\left(x_{n}, T x_{n}\right)=\operatorname{dist}(A, B) .
$$

Note that if $\operatorname{dist}(A, B)=0$, then the sequence $\left\{x_{n}\right\}$ is said to be an approximate fixed point sequence for $T$.

The following lemma guarantees the existence of approximate best proximity sequences for cyclic relatively nonexpansive mappings. 
Lemma 3.6 Let $(A, B)$ be a nonempty, bounded, closed, and convex pair of a convex metric space $(X, d, \mathcal{W})$ such that $A_{0}$ is nonempty, $X$ has the property $(C)$ and $(A, B)$ is proximal compactness. Let $T: A \cup B \rightarrow A \cup B$ be a cyclic relatively nonexpansive mapping. Then there exists an approximate best proximity point sequence for $T$ in $A$.

Proof It follows from Lemma 3.3 that there exists a pair $\left(K_{1}, K_{2}\right) \subseteq(A, B)$ which is minimal with respect to being nonempty, closed, convex, and a $T$-invariant pair of subsets of $(A, B)$ and there exists $\left(x^{*}, y^{*}\right) \in K_{1} \times K_{2}$ such that

$$
\operatorname{dist}\left(K_{1}, K_{2}\right)=d\left(x^{*}, y^{*}\right)=\operatorname{dist}(A, B) .
$$

For any $r \in(0,1)$ put $\alpha:=-r^{2}+2 r$. Then $\alpha \in(0,1)$. Define the mapping $T_{r}: A \cup B \rightarrow A \cup B$ as follows:

$$
T_{r}(x)= \begin{cases}\mathcal{W}\left(T x, y^{*}, r\right) ; & x \in A, \\ \mathcal{W}\left(T x, x^{*}, r\right) ; & x \in B\end{cases}
$$

Since $T$ is cyclic and $(A, B)$ is a convex pair in convex metric space $(X, d, \mathcal{W})$, we conclude that $T_{r}$ is cyclic on $A \cup B$. Now, for each $(x, y) \in A \times B$ we have

$$
\begin{aligned}
d\left(T_{r} x, T_{r} y\right) & =d\left(\mathcal{W}\left(T x, y^{*}, r\right), \mathcal{W}\left(T y, x^{*}, r\right)\right) \\
& \leq r d\left(\mathcal{W}\left(T x, y^{*}, r\right), T y\right)+(1-r) d\left(\mathcal{W}\left(T x, y^{*}, r\right), x^{*}\right) \\
& \leq r\left[r d(T y, T x)+(1-r) d\left(T y, y^{*}\right)\right]+(1-r)\left[r d\left(T x, x^{*}\right)+(1-r) d\left(y^{*}, x^{*}\right)\right] \\
& \leq r^{2} d(x, y)+r(1-r) d\left(T y, y^{*}\right)+r(1-r) d\left(x^{*}, T x\right)+(1-r)^{2} d\left(x^{*}, y^{*}\right) \\
& \leq r^{2} \delta\left(K_{1}, K_{2}\right)+2 r \delta\left(K_{1}, K_{2}\right)-2 r^{2} \delta\left(K_{1}, K_{2}\right)+(1-r)^{2} \operatorname{dist}(A, B) \\
& =\left(-r^{2}+2 r\right) \delta\left(K_{1}, K_{2}\right)+\left(1-\left(-r^{2}+2 r\right)\right) \operatorname{dist}(A, B) \\
& =\alpha \delta\left(K_{1}, K_{2}\right)+(1-\alpha) \operatorname{dist}(A, B) .
\end{aligned}
$$

Hence, for each $r \in(0,1)$ we have

$$
d\left(T_{r} x, T_{r} y\right) \leq \alpha \delta\left(K_{1}, K_{2}\right)+(1-\alpha) \operatorname{dist}(A, B) .
$$

By using Remark 3.1, we conclude that the cyclic mapping $T_{r}$ has a best proximity point, say $p_{r} \in A$, for each $r \in(0,1)$. Thus,

$$
\begin{aligned}
\operatorname{dist}(A, B) & \leq d\left(p_{r}, T p_{r}\right) \\
& \leq d\left(p_{r}, T_{r}\left(p_{r}\right)\right)+d\left(T_{r}\left(p_{r}\right), T p_{r}\right) \\
& =\operatorname{dist}(A, B)+d\left(\mathcal{W}\left(T p_{r}, y^{*}, r\right), T p_{r}\right) \\
& \leq \operatorname{dist}(A, B)+(1-r) d\left(T p_{r}, y^{*}\right) \\
& \leq \operatorname{dist}(A, B)+(1-r) \operatorname{diam}(B)
\end{aligned}
$$


If $r \rightarrow 1^{-}$in the above relation, we obtain

$$
d\left(p_{r}, T p_{r}\right) \rightarrow \operatorname{dist}(A, B) .
$$

That is, there exists a sequence $\left\{x_{n}\right\}$ in $A$ such that $d\left(x_{n}, T x_{n}\right) \rightarrow \operatorname{dist}(A, B)$, which completes the proof.

Here, we state the main result of this paper.

Theorem 3.7 Let $(A, B)$ be a nonempty, bounded, closed, and convex pair of a convex metric space $(X, d, \mathcal{W})$ such that $X$ has the property $(C)$. Assume that $A_{0}$ is nonempty and $(A, B)$ is proximal compactness and satisfies the property $U C$. Let $T: A \cup B \rightarrow A \cup B$ be a cyclic relatively nonexpansive mapping. Let $\left(K_{1}, K_{2}\right) \subseteq(A, B)$ be a minimal closed and convex pair which is $T$-invariant such that $\operatorname{dist}\left(K_{1}, K_{2}\right)=\operatorname{dist}(A, B)$, and $\left\{x_{n}\right\}$ a sequence in $K_{1}$ such that $\lim _{n \rightarrow \infty} d\left(x_{n}, T x_{n}\right)=\operatorname{dist}(A, B)$. Then for all $(p, q) \in K_{1} \times K_{2}$ with $d(p, q)=\operatorname{dist}(A, B)$ we have

$$
\max \left\{\limsup _{n \rightarrow \infty} d\left(x_{n}, q\right), \limsup _{n \rightarrow \infty} d\left(p, T x_{n}\right)\right\}=\delta\left(K_{1}, K_{2}\right) .
$$

Moreover, the set of best proximity points of $T$ is nonempty.

Proof We see from Lemma 3.4 that each point $(p, q) \in K_{1} \times K_{2}$ with $d(p, q)=\operatorname{dist}(A, B)$ contains a diametral point, that is,

$$
\max \left\{\delta_{p}\left(K_{2}\right), \delta_{q}\left(K_{1}\right)\right\}=\delta\left(K_{1}, K_{2}\right)
$$

Let $\left\{x_{n}\right\}$ be the sequence given by the statement, which exists because of Lemma 3.6, and assume that there exists $(u, v) \in K_{1} \times K_{2}$ and $r<\delta(A, B)$ such that $d(u, v)=\operatorname{dist}(A, B)$ and

$$
\limsup _{n \rightarrow \infty} d\left(u, T x_{n}\right) \leq r, \quad \limsup _{n \rightarrow \infty} d\left(x_{n}, v\right) \leq r .
$$

Note that

$$
d\left(T^{2} x_{n}, T x_{n}\right) \leq d\left(T x_{n}, x_{n}\right) \rightarrow \operatorname{dist}(A, B),
$$

as $n \rightarrow \infty$. Since $(A, B)$ has the property $\mathrm{UC}$,

$$
\lim _{n \rightarrow \infty} d\left(T^{2} x_{n}, x_{n}\right)=0
$$

Set

$$
C_{1}:=\left\{y \in K_{2}: \limsup _{n \rightarrow \infty} d\left(x_{n}, y\right) \leq r\right\}
$$

and

$$
C_{2}:=\left\{x \in K_{1}: \limsup _{n \rightarrow \infty} d\left(x, T x_{n}\right) \leq r\right\} .
$$


Note that $\left(C_{1}, C_{2}\right)$ is a nonempty, bounded, and closed pair in $X$. We show that $\left(C_{1}, C_{2}\right)$ is also convex. Let $y_{1}, y_{2} \in C_{1}$ and $\lambda \in[0,1]$. We have

$$
\begin{aligned}
& \limsup _{n \rightarrow \infty} d\left(x_{n}, \mathcal{W}\left(y_{1}, y_{2}, \lambda\right)\right) \\
& \quad \leq \limsup _{n \rightarrow \infty}\left[\lambda d\left(x_{n}, y_{1}\right)+(1-\lambda) d\left(x_{n}, y_{2}\right)\right] \\
& \quad \leq \lambda r+(1-\lambda) r=r .
\end{aligned}
$$

Thus, $C_{1}$ is convex. Similarly, we can see that $C_{2}$ is convex. Besides, by the fact that $(u, v) \in$ $C_{1} \times C_{2}$ we conclude that $\operatorname{dist}\left(C_{2}, C_{1}\right)=\operatorname{dist}(A, B)$. We now verify that $T$ is cyclic on $C_{2} \cup C_{1}$. Suppose that $x \in C_{2}$. Then $T x \in K_{2}$ and $\limsup _{n \rightarrow \infty} d\left(x, T x_{n}\right) \leq r$. It now follows from (6) that

$$
\begin{aligned}
\limsup _{n \rightarrow \infty} d\left(x_{n}, T x\right) & \leq \limsup _{n \rightarrow \infty}\left[d\left(x_{n}, T^{2} x_{n}\right)+d\left(T^{2} x_{n}, T x\right)\right] \\
& \leq \limsup _{n \rightarrow \infty} d\left(x, T x_{n}\right) \leq r
\end{aligned}
$$

that is, $T x \in C_{1}$. Now, let $y \in C_{1}$. Then $T y \in K_{1}$ and

$$
\limsup _{n \rightarrow \infty} d\left(T y, T x_{n}\right) \leq \limsup _{n \rightarrow \infty} d\left(x_{n}, y\right) \leq r
$$

that is, Ty $\in C_{2}$. Hence, $T$ is cyclic on $C_{2} \cup C_{1}$. From the minimality of $\left(K_{1}, K_{2}\right)$ one deduces that $K_{1}=C_{2}$ and $K_{2}=C_{1}$. Since $\lim _{n \rightarrow \infty} d\left(x_{n}, T x_{n}\right)=\operatorname{dist}(A, B)$ and $(A, B)$ is proximal compactness, we may assume that $x_{n} \rightarrow p \in K_{1}$ and $T x_{n} \rightarrow q \in K_{2}$. Therefore, $d(p, q)=\operatorname{dist}(A, B)$ and we have

$$
d(p, y)=\limsup _{n \rightarrow \infty} d\left(x_{n}, y\right) \leq r \quad \text { and } \quad d(q, x)=\limsup _{n \rightarrow \infty} d\left(x, T x_{n}\right) \leq r
$$

for all $(x, y) \in K_{1} \times K_{2}$. Therefore $\delta_{p}\left(K_{2}\right) \leq r<\delta(A, B)$ and $\delta_{q}\left(K_{1}\right) \leq r<\delta(A, B)$, which is a contradiction by the fact that the pair $(p, q)$ contains a diametral point. Hence,

$$
\max \left\{\limsup _{n \rightarrow \infty} d\left(x_{n}, q\right), \limsup _{n \rightarrow \infty} d\left(p, T x_{n}\right)\right\}=\delta\left(K_{1}, K_{2}\right)
$$

On the other hand, $\limsup _{n \rightarrow \infty} d\left(x_{n}, q\right)=d(p, q)=\operatorname{dist}(A, B)$ and

$$
\limsup _{n \rightarrow \infty} d\left(p, T x_{n}\right) \leq \limsup _{n \rightarrow \infty}\left[d(p, q)+d\left(q, T x_{n}\right)\right]=\operatorname{dist}(A, B) .
$$

We now conclude that

$$
\operatorname{dist}(A, B)=\max \left\{\limsup _{n \rightarrow \infty} d\left(x_{n}, q\right), \limsup _{n \rightarrow \infty} d\left(p, T x_{n}\right)\right\}=\delta\left(K_{1}, K_{2}\right),
$$

and so, for each pair $(x, y) \in K_{1} \times K_{2}$ we have

$$
d(x, T x)=d(T y, y)=\operatorname{dist}(A, B) .
$$

This completes the proof of theorem. 
The next corollary is an extension of the classical Goebel-Karlovitz lemma [23, 24] in convex metric spaces.

Corollary 3.8 Let A be a nonempty, bounded, closed, and convex subset of a convex metric space $(X, d, \mathcal{W})$ such that $X$ has the property $(C)$. Assume that $A$ is semi-compactness. Let $T: A \rightarrow A$ be a nonexpansive mapping. Suppose that $K_{1} \subseteq A$ is a minimal closed and convex subset which is $T$-invariant and $\left\{x_{n}\right\}$ is an approximate fixed point sequence in $K_{1}$. Then for each $p \in K_{1}$ we have

$$
\limsup _{n \rightarrow \infty} d\left(p, T x_{n}\right)=\operatorname{diam}(K)
$$

Moreover, the set of fixed points of $T$ is nonempty.

Proof If we consider $A=B$ and $K_{1}=K_{2}$ in Theorem 3.7, then $(A, B)$ has the property UC and the result follows by observing that $\delta\left(K_{1}, K_{2}\right)=\operatorname{diam}\left(K_{1}\right)$.

The following theorem is another version of Theorem 3.7, in the setting of reflexive Banach spaces.

Theorem 3.9 ([7]) Let $(A, B)$ be a nonempty, bounded, closed, and convex pair of a Banach space $X$ such that $(A, B)$ satisfies property UC. Suppose that $T: A \cup B \rightarrow A \cup B$ is a cyclic relatively nonexpansive mapping. Let $\left(K_{1}, K_{2}\right) \subseteq(A, B)$ be a minimal closed and convex pair which is $T$-invariant such that $\operatorname{dist}\left(K_{1}, K_{2}\right)=\operatorname{dist}(A, B)$, and $\left\{x_{n}\right\}$ a sequence in $K_{1}$ such that $\lim _{n \rightarrow \infty}\left\|x_{n}-T x_{n}\right\|=\operatorname{dist}(A, B)$. Then for all $(p, q) \in K_{1} \times K_{2}$ with $\|p-q\|=\operatorname{dist}(A, B)$ we have

$$
\max \left\{\limsup _{n \rightarrow \infty}\left\|x_{n}-q\right\|, \limsup _{n \rightarrow \infty}\left\|p-T x_{n}\right\|\right\}=\delta\left(K_{1}, K_{2}\right) .
$$

Proof At first, we note that every reflexive Banach space is a convex metric space which has the property $(\mathrm{C})$. It is sufficient to consider a convex structure $\mathcal{W}: X \times X \times[0,1] \rightarrow X$ with $W(x, y, \lambda)=\lambda x+(1-\lambda) y$. Moreover, $A_{0}$ is nonempty. Indeed, if $\left(\left\{x_{n}\right\},\left\{y_{n}\right\}\right)$ is a sequence in $A \times B$ such that $\left\|x_{n}-y_{n}\right\| \rightarrow \operatorname{dist}(A, B)$, as $X$ is reflexive and $(A, B)$ is a bounded and closed pair in $X$, the sequence $\left(\left\{x_{n}\right\},\left\{y_{n}\right\}\right)$ has a subsequence $\left(\left\{x_{n_{k}}\right\},\left\{y_{n_{k}}\right\}\right)$ such that $x_{n_{k}} \rightarrow p \in A$ and $y_{n_{k}} \rightarrow q \in B$, where ' $\rightarrow$ ' denotes the weak convergence. It now follows from the weak lower semicontinuity of the norm that

$$
\|p-q\| \leq \liminf _{k \rightarrow \infty}\left\|x_{n_{k}}-y_{n_{k}}\right\|=\operatorname{dist}(A, B),
$$

that is, $A_{0}$ is nonempty. By a similar argument to Theorem 3.7, the result follows.

Remark 3.2 Note that in Theorem 3.9, we cannot deduce the existence of a best proximity point unless we add another condition. For instance, if the sequence $\left\{x_{n}\right\}$, considered in Theorem 3.9, converges to a point in $A$ then the best proximity point set of $T$ will be nonempty. 


\section{Competing interests}

The authors declare that they have no competing interests.

\section{Authors' contributions}

All authors contributed equally to the writing of this paper. All authors read and approved the final manuscript.

\section{Author details}

${ }^{1}$ Department of Mathematics, Ayatollah Boroujerdi University, Boroujerd, Iran. ${ }^{2}$ Department of Mathematics, King Abdulaziz University, P.O. Box 80203, Jeddah, 21589, Saudi Arabia.

\section{Acknowledgements}

This article was funded by the Deanship of Scientific Research (DSR), King Abdulaziz University, Jeddah. The second author acknowledges with thanks DSR for financial support.

Received: 19 April 2014 Accepted: 18 August 2014 Published: 11 September 2014

\section{References}

1. Kirk, WA, Srinivasan, PS, Veeramani, P: Fixed points for mappings satisfying cyclic contractive conditions. Fixed Point Theory 4(1), 79-86 (2003)

2. Eldred, A, Veeramani, P: Existence and convergence of best proximity points. J. Math. Anal. Appl. 323, 1001-1006 (2006)

3. Al-Thagafi, MA, Shahzad, N: Convergence and existence results for best proximity points. Nonlinear Anal. 70, 3665-3671 (2009)

4. Rezapour, S, Derafshpour, M, Shahzad, N: Best proximity points of cyclic $\phi$-contractions on reflexive Banach spaces. Fixed Point Theory Appl. 2010, Article ID 946178 (2010). doi:10.1155/2010/946178

5. Suzuki, T, Kikkawa, M, Vetro, C: The existence of best proximity points in metric spaces with the property UC. Nonlinear Anal. 71, 2918-2926 (2009)

6. Abkar, A, Gabeleh, M: Best proximity points for asymptotic cyclic contraction mappings. Nonlinear Anal. 74 7261-7268 (2011)

7. Espínola, R, Gabeleh, M: On the structure of minimal sets of relatively nonexpansive mappings. Numer. Funct. Anal. Optim. 34, 845-860 (2013)

8. Espínola, R, Fernández-León, A: On best proximity points in metric and Banach spaces. Can. J. Math. 63, 533-550 (2011)

9. Eldred, AA, Kirk, WA, Veeramani, P: Proximal normal structure and relatively nonexpansive mappings. Stud. Math. 171, 283-293 (2005)

10. Al-Thagafi, MA, Shahzad, N: Best proximity pairs and equilibrium pairs for Kakutani multimaps. Nonlinear Anal. 70, 1209-1216 (2009)

11. Al-Thagafi, MA, Shahzad, N: Best proximity sets and equilibrium pairs for a finite family of multimaps. Fixed Point Theory Appl. 2008, Article ID 457069 (2008)

12. Derafshpour, M, Rezapour, S, Shahzad, N: Best proximity points of cyclic $\varphi$-contractions in ordered metric spaces. Topol. Methods Nonlinear Anal. 37, 193-202 (2011)

13. Gabeleh, M, Shahzad, N: Seminormal structure and fixed points of cyclic relatively nonexpansive mappings. Abstr. Appl. Anal. 2014, Article ID 123613 (2014)

14. Kadelburg, Z, Radenović, S: A note on some recent best proximity point results for non-self mappings. Gulf J. Math. 1 36-41 (2013)

15. Pathak, HK, Shahzad, N: Some results on best proximity points for cyclic mappings. Bull. Belg. Math. Soc. Simon Stevin 20, 559-572 (2013)

16. Sadiq Basha, S, Shahzad, N: Best proximity point theorems for generalized proximal contractions. Fixed Point Theory Appl. 2012, 42 (2012)

17. Sadiq Basha, S, Shahzad, N, Jeyaraj, R: Best proximity points: approximation and optimization. Optim. Lett. 7, 145-155 (2013)

18. Sadiq Basha, S, Shahzad, N, Jeyaraj, R: Best proximity point theorems for reckoning optimal approximate solutions Fixed Point Theory Appl. 2012, 202 (2012)

19. Takahashi, W: A convexity in metric space and nonexpansive mappings. Kodai Math. Semin. Rep. 22, 142-149 (1970)

20. Shimizu, T, Takahashi, W: Fixed points of multivalued mappings in certain convex metric spaces. Topol. Methods Nonlinear Anal. 8, 197-203 (1996)

21. Gabeleh, M: Minimal sets of noncyclic relatively nonexpansive mappings in convex metric spaces. Fixed Point Theory (to appear)

22. Gabeleh, M: Proximal quasi-normal structure in convex metric spaces. An. Stiint. Univ. Ovidius Constanta 22, 45-58 (2014)

23. Goebel, K: On the structure of minimal invariant sets for nonexpansive mappings. Ann. Univ. Mariae Curie-Skłodowska 29, 73-77 (1975)

24. Karlovitz, L: Existence of fixed point for nonexpansive mappings in spaces without normal structure. Pac. J. Math. 66 153-156 (1976)

doi:10.1186/1029-242X-2014-350

Cite this article as: Gabeleh and Shahzad: Some new results on cyclic relatively nonexpansive mappings in convex metric spaces. Journal of Inequalities and Applications 2014 2014:350. 